\title{
Knockdown of Cxcl10 Inhibits Mesangial Cell Proliferation in Murine Habu Nephritis Via ERK Signaling
}

\author{
Jie Gao ${ }^{a, b}$ Lingling Wu ${ }^{b}$ Yong Wang ${ }^{b}$ Shaoyuan Cui ${ }^{b}$ Shuwei Duan ${ }^{b}$ \\ Zheyi Dong $^{\mathrm{b}} \quad$ Zhe Feng $^{\mathrm{b}} \quad$ Xiangmei Chen ${ }^{\mathrm{a}, \mathrm{b}}$
}

\begin{abstract}
aDepartment of Nephrology, The Second Hospital of Jilin University, Changchun, Jilin, 'Department of Nephrology, Chinese PLA General Hospital, Chinese PLA Institute of Nephrology, Beijing Key Laboratory of Kidney Disease, State Key Laboratory of Kidney Diseases, National Clinical Research Center for Kidney Diseases, Beijing, People's Republic of China
\end{abstract}

\section{Key Words}

Cxcl10 • Proliferation • ERK • Mesangial proliferative glomerulonephritis

\begin{abstract}
Background/Aims: IFN- $\gamma$-inducible protein 10 (IP-10, CXCL10) has been widely demonstrated to be involved in chemotaxis, cell growth regulation and angiogenesis inhibition. It has been reported that CXCL10 expression is significantly increased in patients with MesPGN (Mesangial proliferative glomerulonephritis). However, the underlying mechanism of CXCL10 in MesPGN reminds unclear. Methods: Wildtype $\left(\mathrm{Cxcl} 10^{+/+}\right)$mice and Cxcl10-deficient $\left(\mathrm{Cxcl} 10^{-/-}\right)$mice were used to generate a murine model of MesPGN. The histological changes in glomeruli were examined by PAS staining (Periodic Acid-Schiff staining), and cell proliferation was detected by PCNA immunohistochemistry staining. The expression of cell cycle regulatory proteins was analyzed by Western blotting and the effects of CXCL10 on primary mouse renal mesangial cells (MRMC) proliferation were detected using the EDU assay. Furthermore, the specific mechanisms by which CXCL10 affected mesangial cells were investigated in vitro using a specific inhibitor. Results: Typical pathological phenotypes were observed in both mouse types, while the $\mathrm{Cxcl} 10^{-/}$mice had lighter accumulation of extracellular matrix, less cell proliferation and diminished up-regulation of cell cycle regulatory proteins compared to $\mathrm{CxCl} 10^{+/+}$mice at day 7. Furthermore, we observed that CXCL10 inhibition resulted in less activation of ERK phosphorylation, and ERK pathway inhibition by a specific inhibitor, U0126, prevented CXCL10 induced MRMC proliferation and the activation of phosphorylated ERK. Conclusions: CXCL10 may aggravate mesangial proliferation in MesPGN by activating the ERK signaling pathway. These results provide a novel insight into the mechanism and potential therapy target of MesPGN.
\end{abstract}

Zhe Feng, Ph. D,

and Xiangmei Chen, MD
Department of Nephrology, Chinese PLA General Hospital, Fuxing Road 28, Beijing 100853, (People's Republic of China)

Tel.+86-010-66935462, E-Mail zhezhe_4025@126.com / xmchen301@126.com

\section{KARGER}




\section{Cellular Physiology Cell Physiol Biochem 2017;42:2118-2129 \begin{tabular}{l|l} 
DOI: 10.1159/000479914 & and Biochemistry \\
Published online: August 14, 2017 & $\begin{array}{l}\text { O 2017 The Author(s). Published by S. Karger AG, Basel } \\
\text { www.karger.com/cpb }\end{array}$ \\
\cline { 2 - 3 }
\end{tabular} \\ Gao et al.: the Mechanism of CXCL10 Promoting Mesangial Cell Proliferation.}

\section{Introduction}

Mesangial proliferative glomerulonephritis (MesPGN) is a common kidney disease that includes IgA nephropathy (IgAN) and non-IgA MesPGN [1, 2]. MesPGN is known to be an autoimmune inflammatory disease, and it is well-defined by an increased cell number and extracellular matrix in the glomerular mesangium [3,4]. Pathophysiological roles of chemokines and their cognate receptors have shed light on the detailed molecular mechanisms of glomerulonephritis. Recent studies on chemokines have expanded the understanding of their function beyond leukocyte migration to glomeruli, including homeostasis, development and injury of resident cells in glomeruli $[5,6]$.

IFN- $\gamma$-inducible protein 10 (IP-10, CXCL10) is a small chemokine that belongs to the CXC chemokine family [7]. It can be secreted by leukocytes and tissue cells, including renal mesangial cells, in response to IFN- $\gamma$ and acts through chemokine receptor CXCR3 [8-10]. It is constitutively expressed and up-regulated in a pro-inflammatory cytokine milieu [11]. The major function of CXCL10 is to selectively recruit immune cells at inflammation sites, but it also plays a role in cell growth and angiostasis [12]. In the last few years, strong experimental and clinical evidence has been obtained that supports CXCL10 is involved in the development of glomeruli diseases $[13,14]$. In our previous study, we found that the expression level of CXCL10 was significantly increased based on the real-time PCR and Western blot results from Habu snake venom (HSV)-induced nephritis models (Habu nephritis). However, the exact role and specific mechanisms by which CXCL10 affected mesangial cells in MesPGN remained undefined.

To determine the function of CXCL10 in MesPGN, we used Cxcl10-deficient mice (Cxcl10 $\left.{ }^{\prime}-\right)$ and wildtype $\left(\mathrm{Cxcl} 10^{+/+}\right)$mice to generate a Habu nephritis model. The clinical features and cell proliferation were examined and analyzed. We found that $\mathrm{Cxcl} 10^{\%}$ mice exhibited a mitigated proliferation phenotype with lighter accumulation of the extracellular matrix and fewer cells in the glomeruli. In addition, the Western blot results showed that the expression levels of cell cycle regulatory proteins were higher in $\mathrm{Cxcl} 10^{+/+}$mice than in Cxcl10\% mice. Furthermore, the specific mechanisms by which CXCL10 affected mesangial cells were investigated in vitro using cultured primary mouse renal mesangial cells (MRMC).

\section{Materials and Methods}

\section{Animal model}

Cxcl10\% mice were purchased from The Jackson laboratory (Stock No: 006087, USA) and wildtype C57Bl/6 mice were purchased from Vital River Laboratories (Beijing, China). All animals were housed in cages at constant room temperature $\left(20^{\circ} \mathrm{C}\right)$ and humidity $(70 \%)$ under a controlled light-dark cycle in the Experimental Animal Center of the PLA General Hospital. A single intravenous injection of Habu snake venom (HSV, Wako Pure Chemical Industries, Osaka, Japan) at a dose of $2.5 \mathrm{mg} / \mathrm{kg}$ bodyweight was given to 6-8-week-old animals to generate a Habu nephritis model. Control mice $(n=6)$ were injected with an equal volume of saline. The mice were sacrificed at $0,1,3,7$ and 14 days after injection ( 6 mice per group), and the renal cortex was isolated. Animal welfare and experimental procedures were performed in accordance with the Guide for the Care and Use of Laboratory Animals (National Research Council of USA, 1996).

\section{Histological analysis}

Kidney samples were fixed in 10\% formalin and dehydrated using a graded ethanol series. Tissues were embedded in paraffin, sectioned and stained with periodic acid-Schiff (PAS) reagent. The numbers of cells in at least 20 glomeruli per murine kidney section were counted to quantify the degree of cell proliferation [15]. The mesangial hypercellularity index was used to assess the severity of hypercellular lesions as follows: 0 , no hypercellularity, with fewer than three cells per mesangial area; 1 , focal mild hypercellularity, $<50 \%$ of glomeruli with three to five cells per mesangial area; 2, diffuse mild hypercellularity or focal segmental prominent hypercellularity, the latter with more than five cells per mesangial area; and 3, diffuse global prominent hypercellularity. 20 randomly selected glomeruli from the renal cortex of each mouse were scored $[16,17]$. 


\section{Cellular Physiology Cell Physiol Biochem 2017;42:2118-2129 \begin{tabular}{l|l} 
DOI: 10.1159/000479914 & and Biochemistry 2017 The Author(s). Published by S. Karger AG, Basel \\
Published onlne: August 14, 2017 & $\begin{array}{l}\text { O } \\
\text { www.karger.com/cpb }\end{array}$
\end{tabular} \\ Gao et al.: the Mechanism of CXCL10 Promoting Mesangial Cell Proliferation.}

\section{Immunohistochemistry}

PCNA immunohistochemistry staining was used to detect cell proliferation. Paraffin sections $(4 \mu \mathrm{m})$ were deparaffinized in xylene and rehydrated in alcohol. Heat-induced epitope retrieval was performed prior to immunostaining for PCNA. Endogenous peroxidase activity and nonspecific binding in the sections was blocked by 3\% hydrogen peroxide and normal serum. The presence of PCNA protein was immunohistochemically demonstrated in tissue specimens by the indirect avidin-biotinylated peroxidase complex method (Vecta-Stain Elite ABC Kit, Vector laboratories, Burlingame, CA, USA) with rabbit antiPCNA Ab (Santa Cruz Biotechnology, USA). For negative controls, the primary antibody was replaced with phosphate-buffered saline (PBS). The PCNA positive rates were calculated as the number of positive cells relative to all glomerular cells.

\section{Cell culture}

Primary mouse renal mesangial cells (MRMC) were purchased from ScienCell Research Laboratories (Cat. \#M4200-57, USA) and were maintained in Mesangial Cell Medium (MCM, Cat. \#4201) supplemented with $10 \mathrm{ml}$ of fetal bovine serum (FBS, Cat. No. 0010), $5 \mathrm{ml}$ of mesangial cell growth supplement (MsCGS, Cat. No. 4252), and $5 \mathrm{ml}$ of penicillin/streptomycin solution (P/S, Cat. No.0503) in a humidified $5 \% \mathrm{CO}_{2}$ atmosphere. Cells were synchronized by incubation with $0.1 \%$ FBS-MCM for $24 \mathrm{~h}$. To determine the effect of CXCL10 on cell proliferation, the subconfluent quiescent cells were incubated with recombinant mouse CXCL10 (R\&D, Cat. 466-CR/CF) at a concentration of 1, 10 or $100 \mathrm{ng} / \mathrm{ml}$. Recombinant human PDGF-BB Protein (R\&D, Catalog \# 220-BB) at the concentration of $10 \mathrm{ng} / \mathrm{ml}$ was used as a positive control. At $48 \mathrm{~h}$ after stimulation, MRMC cells were collected, and the relevant detections were performed.

\section{Cell proliferation assay}

Cell proliferation was analyzed with the Click-iT® Plus EdU Alexa Fluor® 555 Imaging Kit (Invitrogen, Cat. C10638) according to the manufacturer's instructions. In brief, cells were incubated in a 6-well culture plate and stimulated by recombinant CXCL10 for $48 \mathrm{~h}$. Then, the medium was replaced by medium supplemented with optimized EDU at a concentration of $10 \mu \mathrm{M}$ for $24 \mathrm{~h}$. After treatment, cells were fixed with $4 \%$ formaldehyde, permeabilized with $0.5 \%$ TritonX-100, washed with 3\% BSA in PBS, incubated with Click-iT® reaction cocktail for $30 \mathrm{~min}$ at room temperature and incubated with DAPI reaction buffer for $10 \mathrm{~min}$ at room temperature while protected from light. Cells were observed by fluorescence microscopy (Olympus, Tokyo, Japan). The nuclei of proliferating cells were then stained red.

\section{Cell migration assay}

Cells were seeded into 6-well plates and cultured under standard condition. When the cells reached confluence, the center of the culture dish was scratched with a $200 \mu \mathrm{l}$ pipette tip. After washing twice with PBS, the cells were incubated for $72 \mathrm{~h}$ with or without medium containing recombinant mouse CXCL10. Cell migration was determined by measuring the mean open wound area as a percentage of the initial wound area by phase contrast microscopy [18].

\section{Immunofluorescence}

The cells were grown on the sterile coverslips and stimulated by recombinant CXCL10 for $48 \mathrm{~h}$. The cells were fixed with 4\% paraformaldehyde for $15 \mathrm{~min}$ and permeabilized using $0.2 \%$ Triton-X100 for 5-10 min. After washed with PBS, the cells were blocked with rabbit anti-Ki67 antibody (Abcam, USA) followed by Cy3-conjugated anti-rabbit secondary antibody (red). DAPI was used as a counterstain. The results were analyzed under the fluorescence microscopy (Olympus, Tokyo, Japan).

\section{Western blot analysis}

The glomeruli and cells were lysed in RIPA buffer containing a protease inhibitor cocktail $(1 \mathrm{lg} / \mathrm{ml}$ leupeptin, $1 \mathrm{lg} / \mathrm{ml}$ aprotinin, and $100 \mu \mathrm{M}$ PMSF) and centrifuged (30 min, $4{ }^{\circ} \mathrm{C}$, and 15, $\left.000 \mathrm{rpm}\right)$. Protein concentrations were determined using a BCA Protein Assay Kit (Thermo Fisher Scientific, USA). In total, $30 \mu \mathrm{g}$ of total protein per sample was separated by 8-15\% SDS- PAGE and then transferred to membranes, which were blocked with blocking buffer and incubated overnight at $4{ }^{\circ} \mathrm{C}$ with primary antibodies against cyclin D1, cyclin D3, CDK2, CDK4, CDK6 (Santa Cruz Biotechnology, USA), ERK, p-ERK (Cell Signaling Technology, USA), p21, p27 (Novus Biologicals, USA) and $\beta$-actin (Abcam, USA). The samples were then incubated with 


\section{Cellular Physiology Cell Physiol Biochem 2017;42:2118-2129

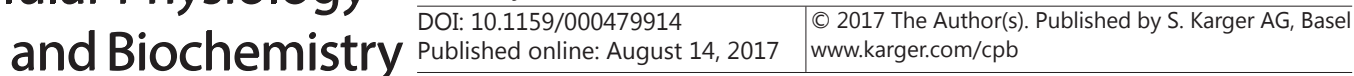

Fig. 1. Clinical features in $\mathrm{Cxcl} 10^{+/+}$and $\mathrm{Cxcl} 10^{-}$ 1 mice. RT-PCR (A) and western blot (B) analysis of total Cxcl10 mRNA and CXCL10 protein isolated from the kidneys of wildtype mice at the indicated times after injection. The signal intensity was quantified and the intensities of the protein bands were presented as ratios to those of the $\beta$-actin bands. (C) Periodic acid-Schiff (PAS) staining of renal tissues obtained at the indicated days after HSV injection. Cxcl10 $\%$ mice exhibited mitigation of extracellular matrix accumulation and cell proliferation in Habu nephritis murine glomeruli. (D) Glomerular nucleated cells in both $\mathrm{Cxcl}_{10}{ }^{+/+}$and $\mathrm{Cxcl} 10^{-/}$ mice were counted $(n=6$ per group and 20 glomeruli per mouse). (E) The hypercellularity index of renal tissues obtained at the indicated days in the two types of mice $(n=6$ per group and 20 glomeruli per mouse). Results are expressed as mean values ( $\pm \mathrm{SD})$; ${ }^{*} \mathrm{P}<0.05$ versus the control group, $\Delta \mathrm{P}<0.05$ versus the Cxcl10\% mice at the indicated days.

secondary antibody. Image J software was used for blot analysis. The intensities of the protein bands are presented as ratios to that of $\beta$-actin or total ERK, and data from the control group were arbitrarily set as 1.0.

\section{Statistical analysis}

All data analyses were performed using SPSS 11.0 software (SPSS Inc., Chicago, IL, USA). The data were expressed as the mean $\pm \mathrm{SD}$. Comparisons among the groups were conducted using ANOVA. $\mathrm{P}<0.05$ was considered significant.

\section{Results}

Mitigation of extracellular matrix accumulation and cell proliferation in Habu nephritis murine glomeruli by blockade of CXCL10

To examine the role of CXCL10 in mesangial proliferative glomerulonephritis, we induced a Habu nephritis mouse model by administering a single intravenous injection of Habu snake venom (HSV) to both Cxcl10-deficient (Cxcl10 ${ }^{-/}$) mice and wildtype (Cxcl10 ${ }^{+/+}$) mice. After treatment with HSV, we quantified the expression of Cxcl10 mRNA at 0, 1, 3, 7 and 14 days in C57BL/ 6 wildtype mice. A marked increase expression of Cxcl10 mRNA was observed in whole kidney tissue, which was 26 -fold over baseline levels at $3 \mathrm{~d}$, and 20 -fold 


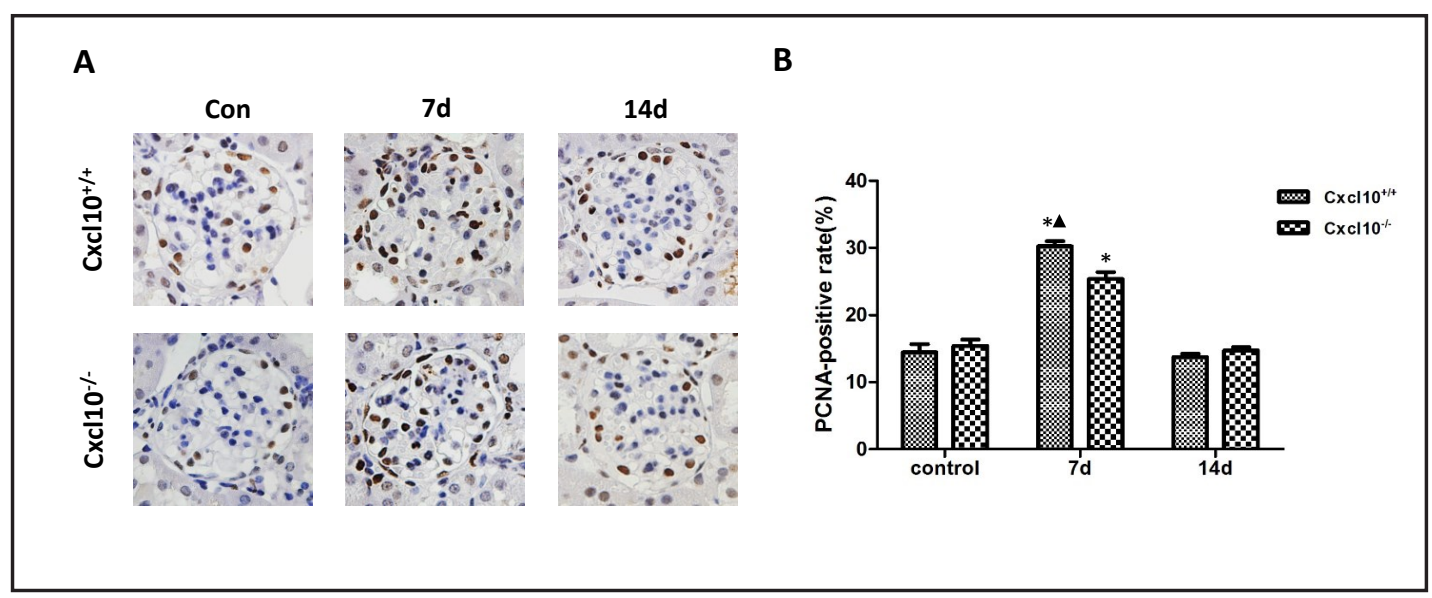

Fig. 2. Proliferation rate assessed by PCNA immunostaining. (A) PCNA immunohistochemistry of glomeruli at the indicated days in both $\mathrm{Cxcl} 10^{+/+}$and $\mathrm{Cxcl} 10^{\%}$ mice to evaluate cell proliferation rate. (B) The PCNApositive rate was lower in $\mathrm{Cxcl} 10^{-/}$mice than that in the $\mathrm{Cxcl} 10^{+/+}$mice $(\mathrm{n}=6$ per group and 20 glomeruli per mouse). Results are expressed as mean values $( \pm \mathrm{SD})$; ${ }^{*} \mathrm{P}<0.05$ versus the control group, ${ }^{\Delta} \mathrm{P}<0.05$ versus the $\mathrm{Cxcl} 10^{-/}$mice at the indicated days.

at 7 d. (Fig. 1A). We then determined the expression of CXCL10 protein by Western blot at the indicated times after HSV administration. CXCL10 protein was induced after injection in wildtype mice (Fig. 1B), corresponding to maximal mRNA expression.

PAS staining was preformed to assess the morphological changes in the glomeruli. Both $\mathrm{Cxcl} 10 \%$ and $\mathrm{Cxcl} 10^{+/+}$mice exhibited typical pathological phenotypes, mesangiolysis and mesangial proliferation. The mesangial dissolution appeared on day 1 with decreased cells, which peaked on day 3 with fibrinoid material deposition. Additionally, diffuse hypercellularity and mesangial matrix accumulation peaked at day 7 and decreased by day 14 after HSV injection (Fig. 1C).

Compared with $\mathrm{Cxcl} 10^{+/+}$mice, the $\mathrm{Cxcl} 10^{-/}$group had lighter accumulation of extracellular matrix and fewer cells per glomerulus, especially at day 7. The difference was statistically significant. Additionally, there was no difference in the number of glomerular nucleated cells between the $\mathrm{Cxcl} 10^{+/+}$and $\mathrm{Cxcl} 10^{-/}$mice on day 0 (Fig.1D). According to semi-quantitative analysis, the hypercellularity index significantly lower in the Cxcl10\% group than in the $\mathrm{Cxcl} 10^{+/+}$group at day7 (Fig. 1E).

To clarify the proliferation promoting effect of CXCL10 in MesPGN, we used PCNA, proliferation cell nuclear antigen, to detect glomerulus proliferation among the $\mathrm{Cxcl} 10^{+/+}$ and $\mathrm{Cxcl} 10^{\%}$ mice by immunohistochemistry staining. The results showed that the cell proliferation rate began to increase from day 1 , which peaked on day 7 , and recovered on day 14 (Fig. 2A). Moreover, the numbers of PCNA-positive cells were counted in at least 20 glomeruli per mouse kidney section to quantify the degree of cell proliferation. The results showed that the $\mathrm{Cxcl} 10^{-/}$mice $(25.40 \% \pm 1.77)$ expressed a lower percentage of PCNA positive cells than $\mathrm{Cxcl} 10^{+/+}$mice $(30.26 \% \pm 1.31)$ at day $7(\mathrm{p}<0.05)$ (Fig. $\left.2 \mathrm{~B}\right)$. These results suggested that CXCL10 played a role in the proliferation process in Habu nephritis.

CXCL10 deficiency diminished the up-regulation of cell cycle regulatory protein expression

The results shown above indicated that lack of CXCL10 reduced the proliferation of glomerular cells, implying that inhibition of the cell cycle might be responsible for the reduced proliferation. Therefore, we evaluated the expression of several key proteins involved in the cell cycle, such as Cyclin D1, Cyclin D3, Cyclin-dependent kinase 2 (CDK2), Cyclin-dependent kinase 4 (CDK4) and Cyclin-dependent kinase 6 (CDK6) in both groups. The results showed that all these protein expression levels were up-regulated on day 7 compared with day 0 in $\mathrm{Cxcl} 10^{+/+}$mice, which were similar to the PCNA staining pattern. And the protein expression 


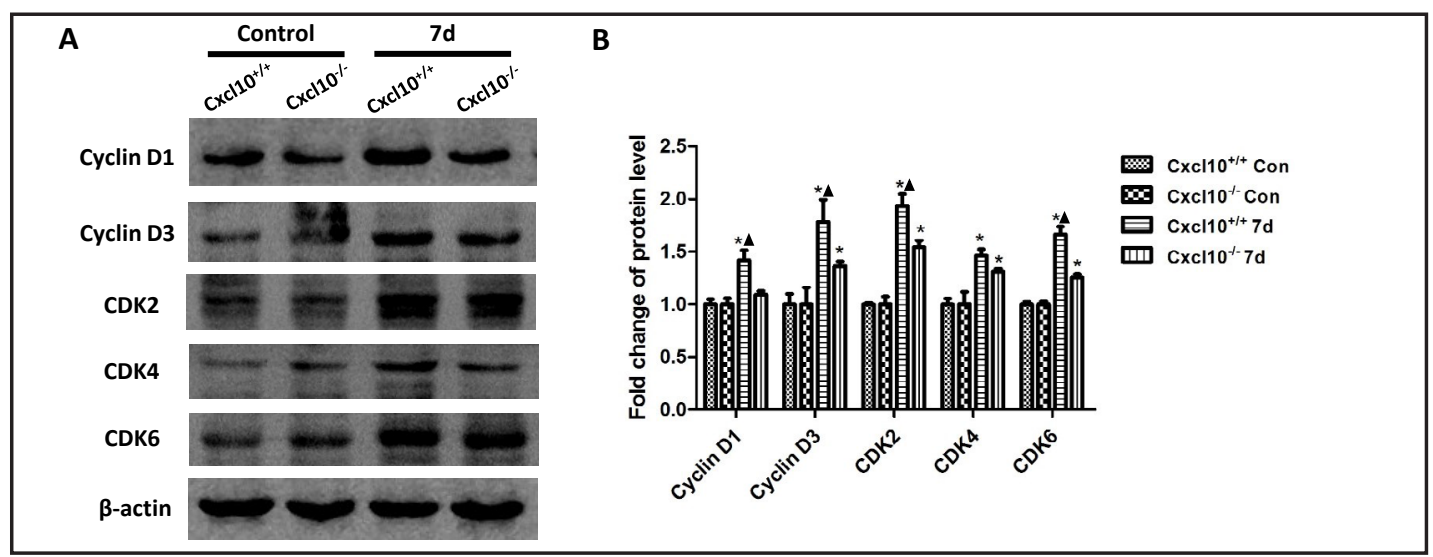

Fig. 3. The effect of CXCL10 up-regulation of cell cycle regulatory protein expression. (A)Western blot analysis of cyclin D1, cyclin D3, CDK2, CDK4 and CDK6 protein expression at the indicated days of Habu nephritis in both $\mathrm{Cxcl} 10^{+/+}$and $\mathrm{Cxcl} 10^{-/-}$mice. (B) The expression levels of positive cell cycle regulatory proteins were quantified by densitometry. The intensities of the protein bands were presented as ratios to those of the $\beta$-actin bands; data from the control group were arbitrarily set as 1.0. CXCL10 deficiency diminished the upregulation of cell cycle regulatory protein expression. Results are expressed as mean values $( \pm \mathrm{SD}) ;{ }^{*} \mathrm{P}<0.05$ versus the control group, ${ }^{\wedge} \mathrm{P}<0.05$ versus the $\mathrm{Cxcl} 10^{-/-}$mice at the indicated days.

Fig. 4. The effect of CXCL10 up-regulation on MRMC proliferation. (A)EDU incorporation assay of MRMC proliferation (red, EDU; blue, DAPI; pink, merged). MRMC were incubated for $48 \mathrm{~h}$ in the absence or presence of different concentrations of CXCL10, or PDGF-BB, and with EDU for the subsequent 24 h. One representative experiment is shown. (B) The percentage of EDUpositive cells among the total number of cells represents the degree of proliferation. Results are expressed as mean values $( \pm S D)$; $* \mathrm{P}<0.05$ versus the con-

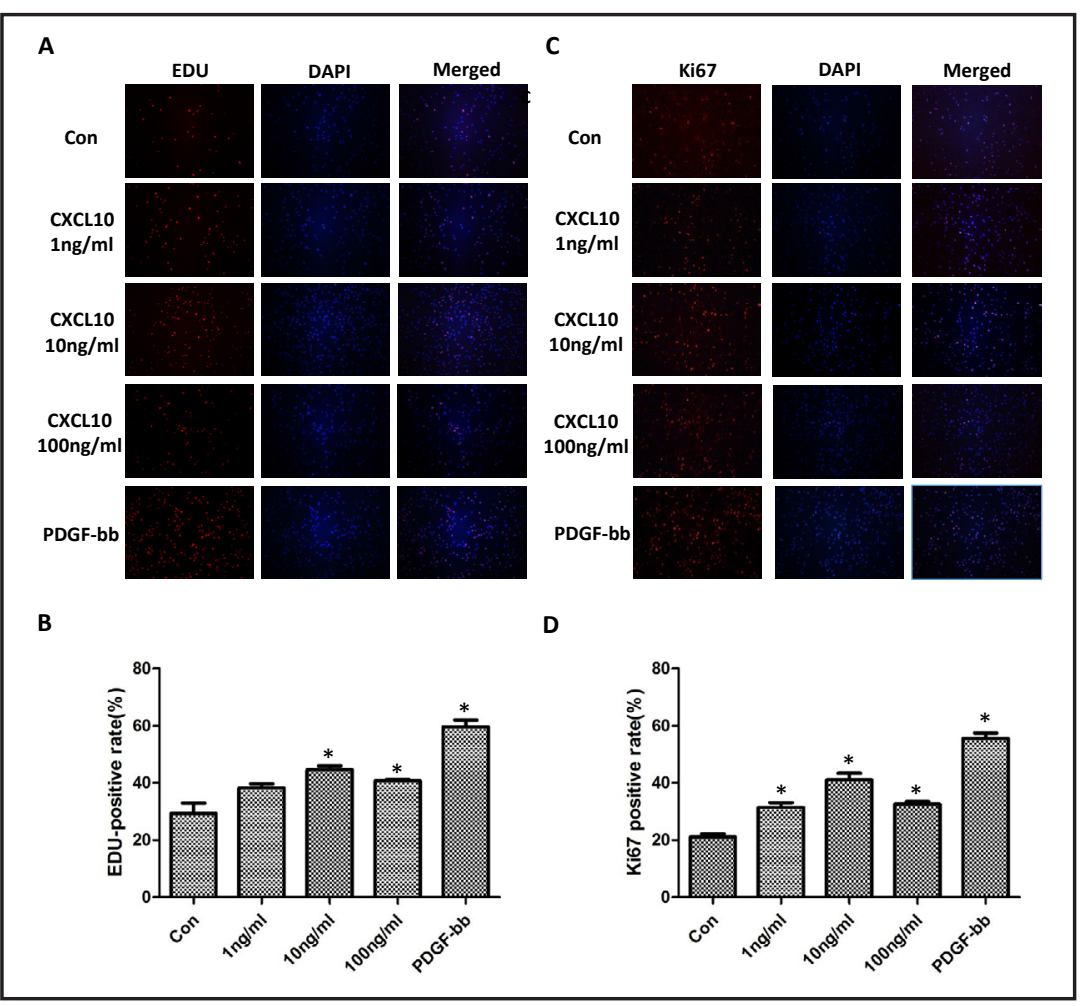
trol group. (C)Immuno-

fluorescence of Ki67 on MRMC (red, Ki67; blue, DAPI; pink, merged). MRMC were incubated for $48 \mathrm{~h}$ in the absence or presence of different concentrations of CXCL10, or PDGF-BB. One representative experiment is shown. (D)The percentage of Ki67-positive cells among the total number of cells represents the degree of proliferation. Results are expressed as mean values $( \pm \mathrm{SD}) ;{ }^{*} \mathrm{P}<0.05$ versus the control group.

levels of Cyclin D3, CDK2, CDK4 and CDK6 were statistically increased on day 7 compared with controls in $\mathrm{Cxcl10} \%$ mice. While focusing on day $7, \mathrm{Cxcl} 10^{\%}$ mice exhibited a lower 


\section{Cellular Physiology Cell Physiol Biochem 2017;42:2118-2129 and Biochemistry Published online: August 14, 2017 年 $\begin{aligned} & \text { O 2017 The Author(s). Published by S. Karger AG, Basel } \\ & \text { www.karger.com/cpb }\end{aligned}$

Fig. 5. CXCL10 promotes MRMC migration. The wound healing assay showed the migration ability of MRMC incubated in the absence or presence of different concentrations of CXCL10 for 72 h. (B)The mean open wound area as a percentage of the initial wound area at $72 \mathrm{~h}$ indicates a significantly accelerated wound closure for CXCL10 treatment compared to controls. Results are expressed as mean values $( \pm \mathrm{SD}) ;{ }^{*} \mathrm{P}<0.05$ versus the control group.

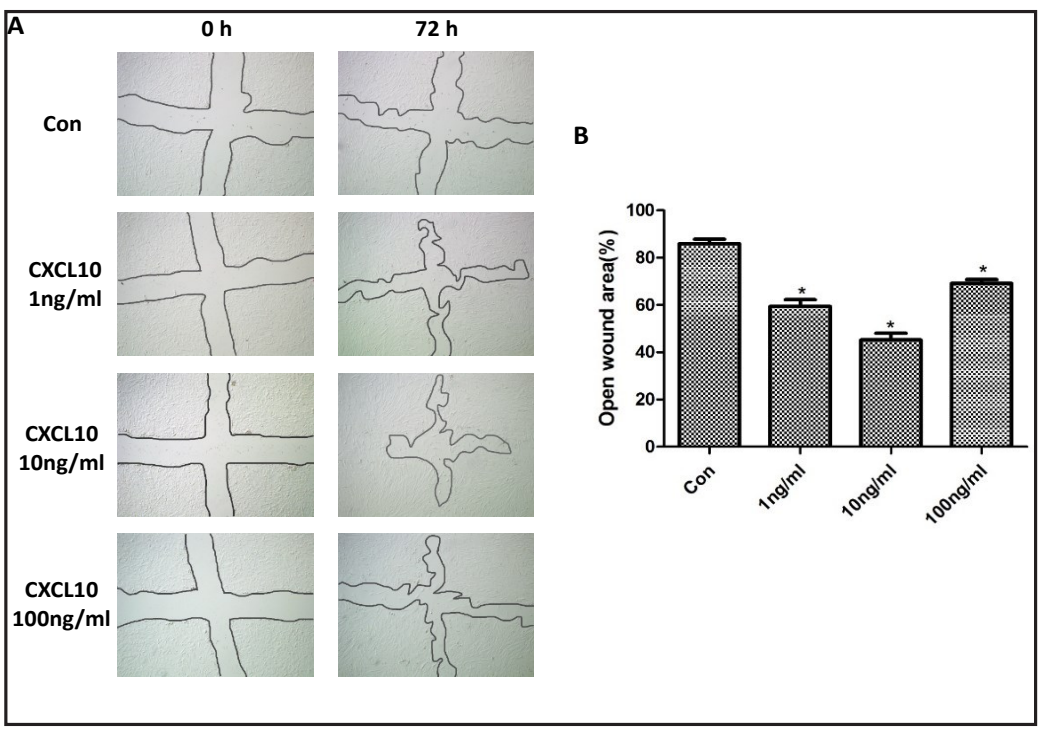

expression of these cell cycle regulatory proteins compared to the $\mathrm{Cxcl} 10^{+/+}$group (Fig. $3)$. These changes indicated that CXCL10 mediates cell proliferation in MesPGN through regulating the cell cycle proteins.

CXCL10 stimulated cultured mouse mesangial cell proliferation and migration in vitro

In vivo experimental results indicated that CXCL10 played a proliferation role in MesPGN. To explore the direct role of CXCL10 in mesangial cell proliferation, we used recombinant mouse CXCL10 to stimulate cultured primary mouse renal mesangial cells (MRMC) in vitro. To this end, MRMC were serum-free starved for $24 \mathrm{~h}$ to deplete growth factors and they were then incubated with different concentration of recombinant CXCL10 protein, as described in the cell culture. PDGF-BB, one of the most effective growth factors of MRMC described thus far, was used as a positive control [13]. The proliferative response of MRMC to CXCL10 was observed $48 \mathrm{~h}$ after cytokine addition at concentration 1 to $100 \mathrm{ng} / \mathrm{ml}$ and reaching a plateau at $10 \mathrm{ng} / \mathrm{ml}$. As shown in Fig. 4, the percentage of EDU-positive cells and the number of Ki67-positive cells was significantly increased with administration of recombinant CXCL10 protein compared with controls. At least in this system, CXCL10 were less active than PDGF even at maximal effect $(10 \mathrm{ng} / \mathrm{ml})$.

Beyond proliferation, CXCL10 could also influence MRMC migration. Mesangial cells were cultured on tissue culture plates in the absence or presence of different concentrations of CXCL10 for $72 \mathrm{~h}$ after a central scratch was performed. The results showed that denuded areas were restored more rapidly in CXCL10-treated cells after scratching especially at concentration $10 \mathrm{ng} / \mathrm{ml}$ compared to control IgG-treated cells (Fig. 5). These results indicated that CXCL10 can stimulate the proliferation and migration of MRMC in vitro.

\section{CXCL10 modulates mesangial cell proliferation through ERK signaling pathways}

The ERK pathway plays a critical role in modulating cell proliferation and survival. It can be activated in response to many soluble factors, including chemokines. Therefore, we detected the expression of phosphorylation ERK in both groups at day 7, which is the most obvious time of proliferation. ERK phosphorylation had the same increased pattern in these two groups, as assessed by Western blot, while $\mathrm{Cxcl} 10^{-/}$mice exhibited less activation of ERK phosphorylation compared with $\mathrm{Cxcl} 10^{+/+}$mice, which is consistent with the cyclin expression pattern (Fig. 6A\&B). Furthermore, we harvested the protein from CXCL10treated mesangial cells and found that CXCL10 treatment markedly enhanced the expression 
Fig. 6. CXCL10

promotes proliferation via ERK signaling pathways. (A\&B) The amount of phosphorylated ERK protein (p-ERK) at $7 \mathrm{~d}$ was assessed by Western blot, while Cxcl10/ mice exhibited less activation of p-ERK compared with $\mathrm{Cxcl}^{+/ /+}$ mice. (C\&D) Serum starved MRMC were incu-

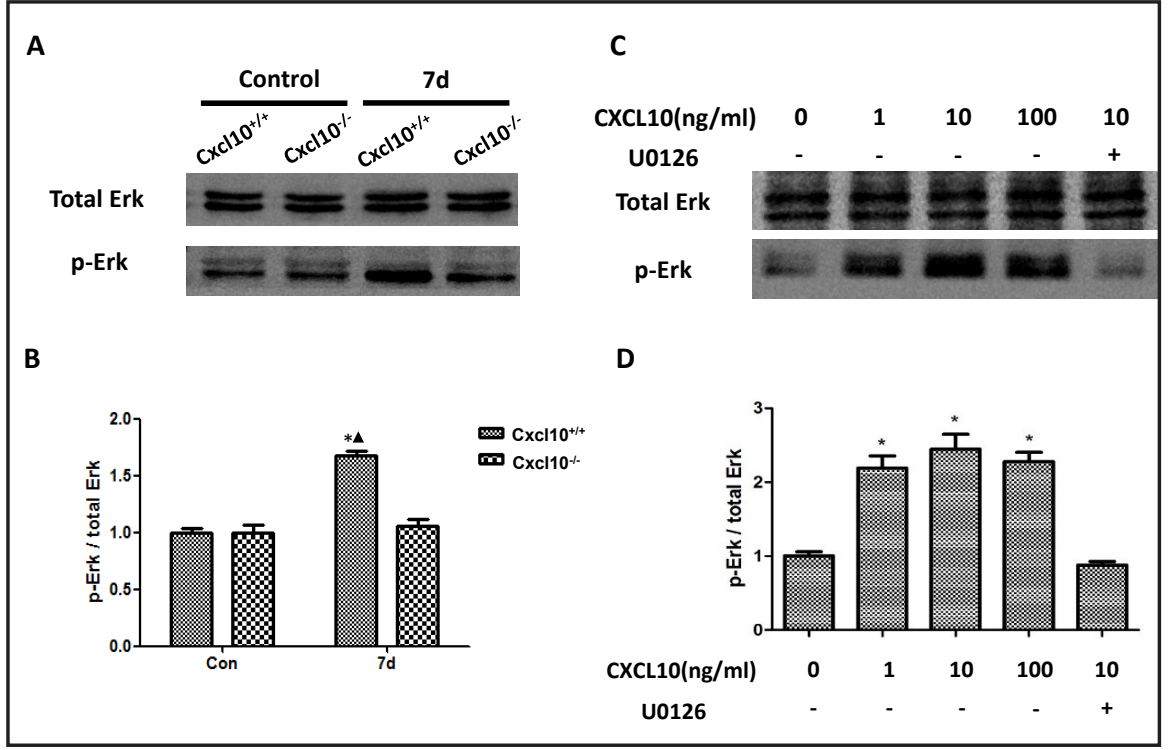
bated with differ-

ent concentrations of CXCL10 for $48 \mathrm{~h}$, or pretreated with U0126 for 30 min before incubated with $10 \mathrm{ng} /$ $\mathrm{ml}$ CXCL10. The phosphorylated ERK was significantly increased after treatment with CXCL10 and was abolished by pretreatment with U0126. The intensities of the protein bands were presented as ratios to those of the total ERK bands; data from the control group were arbitrarily set as 1.0. Results are expressed as mean values $( \pm \mathrm{SD}) ;{ }^{\wedge} \mathrm{P}<0.05$ versus the $\mathrm{Cxcl} 10^{\%} \%$ mice at the indicated days.

of phosphorylation ERK in MRMC. Next, ERK inhibitor U0126 was used to confirm the association between ERK phosphorylation and proliferation effect induction after CXCL10 treatment. As shown in Fig. 6C\&D, phosphorylated ERK was significantly increased after treatment with CXCL10 for $48 \mathrm{~h}$ and was abolished by 30 minutes of pretreatment with $10 \mu \mathrm{M}$ U0126. These findings suggested that CXCL10 may activate the ERK pathway to modulate mesangial cell proliferation.

\section{Discussion}

Mesangial proliferative glomerulonephritis (MesPGN) is the most common type of glomerulonephritis in China [19]. Currently, the pathogenesis of MesPGN remains unclear, but it may be primarily related to genetic immune abnormalities and other factors. Our previous study found that the CXCL10 level was significantly increased in Habu nephritis models by real-time PCR and Western blot analysis. In this study, we explored the potential role and mechanisms by which CXCL10 affects mesangial cells in a murine MesPGN model and confirmed that the chemokine CXCL10 can regulate the mesangial cell proliferation through activating ERK signaling pathway.

MesPGN is characterized by mesangial cell proliferation that is accompanied by mesangial matrix expansion [19]. In general, the mesangial cells response to the pathological stimuli are associated with the following main events of glomerular injury: leukocyte infiltration, cell proliferation and fibrosis. It has demonstrated that glomerular injury may be mediated by adhesion molecules and chemokines, which can be locally synthesized and secreted by mesangial cells [3]. Anti-Thy1 antibody-induced glomerulonephritis in rats and Habu snake venom (HSV)-induced glomerulonephritis in mice are the classical experimental models that exhibit glomerular lesions similar to those of human MesPGN [20, 21]. Therefore, HSV was used to establish a murine model of MesPGN. PAS staining results showed the pathological process was consistent with previous reports in which there was a dissolution phenotype 


\section{Cellular Physiology Cell Physiol Biochem 2017;42:2118-2129 \begin{tabular}{ll|l} 
DOI: 10.1159/000479914 & O 2017 The Author(s). Published by S. Karger AG, Basel \\
www.karger.com/cpb
\end{tabular} \\ Gao et al.: the Mechanism of CXCL10 Promoting Mesangial Cell Proliferation.}

during the early stages of modeling, which was followed by mesangial proliferation and mesangial matrix accumulation that returned to normal on day 14 after HSV injection [22].

Considering that an inflammation-related chemokine CXCL10 may play an important role in the pathological process of MesPGN, we used Cxcl10-deficient mice to generate the Habu nephritis model. Compared with the wildtype group, Cxcl10 $\%$ mice exhibited a light proliferation phenotype. Similar to the histological manifestations, the number of glomerular nucleated cells and the hypercellularity index increased more noticeably in the wildtype mice on day 7. This suggested that CXCL10 might be involved in cell proliferation in the MesPGN.

(C-X-C motif) ligand (CXCL)10/interferon (IFN)- $\gamma$-induced protein 10 (IP-10) belongs to the CXC subfamily chemokine containing a single and variable amino acid between the first two of four highly conserved cysteine residues and exerts its function through binding to the chemokine (C-X-C motif) receptor 3 (CXCR3) $[7,10,23]$. As the name implies, this chemokine can be secreted in response to interferon gamma (IFN- $\gamma$ ) induction by a wide variety of cell types, such as endothelial cells, fibroblasts, keratinocytes, monocytes, and $\mathrm{T}$ lymphocytes, but secretion can also be induced by lipopolysaccharide and pro-inflammatory cytokines, such as interferon alpha (IFN- $\alpha$ ), interferon beta (IFN- $\beta$ ), and tumor necrosis factor-alpha (TNF- $\alpha$ ), depending on the cell type [9, 24-27]. CXCL10 has a wide spectrum of biological and physiological activities, including chemotaxis $[28,29]$, induction of apoptosis [30], regulation of cell growth and mediation of angiostatic effects [12, 31,32]. Several studies have demonstrated that CXCL10 is involved in human glomerulopathy, including mesangial proliferative glomerulonephritis (GN), rapidly progressive GN, membranoproliferative GN, lupus nephritis, and nephrotoxic nephritis [14, 33-35]. More importantly, CXCL10 has been identified as a major biological marker that mediates the disease severity and may be utilized as a prognostic indicator, such as in renal-allograft dysfunction [36], acute kidney injury [37], and lupus nephritis [38].

In previous study, Wu L et al. [39] used Mxi1-deficient mice, which were on FVB/N background, to generate Habu nephritis model and found that Mxi1 inactivation induced the expression of CXCL10 and aggravated the mesangial cell apoptosis. Habu nephritis mouse model is characterized by mesangiolysis and mesangial proliferation. Wu L et al. concerned about mesangial dissolution, which appeared on day 1, and suggested that CXCL10 induced Mxi1-inactivated mesangial cell apoptosis. However, other studies reported that CXCL10 can be secreted by mesangial cells and human mesangial cells (HMC) proliferation can be induced by CXCL10 stimuli $[13,14]$. In our study, we used Cxcl10-deficient mice, which were on C57BL/6 background, to generate Habu nephritis model. We focused on mesangial proliferation, which peaked on day 7 after HSV injection and revealed that CXCL10 promoted the mesangial proliferation. These results suggested that the dominant role of CXCL10 in different stage of disease processes is various. In addition, difference in mouse strains and gene knockout may lead to complex genetic background and cause complicated manifestations, although this clearly needs to be studied in more detail.

To further investigate the differences in the proliferation level between Cxcl10 $10^{+/+}$and $\mathrm{Cxcl} 10^{-/}$mice, we used PCNA immunohistochemistry staining to detect the rate of proliferation in glomeruli and Western blot analysis to evaluate the expression levels of cell cycle regulatory proteins. The PCNA and cell cycle regulatory proteins are essential for understanding the mechanisms involved in controlling cell proliferation [40]. The results showed that the percentage of PCNA positive cells was higher in the $\mathrm{Cxcl} 10^{+/+}$mice on day 7 compared with $\mathrm{Cxcl} 10^{-}$mice. The mechanism of cell cycle regulation is the reciprocity of cyclins, cyclin-dependent kinases (CDKs), and CDKIs. We detected the protein expression patterns of Cyclin D1, Cyclin D3, CDK2, CDK4 and CDK6. The results showed that Cxcl10\% mice exhibited lower expression of these cell cycle regulatory proteins than wildtype mice on day 7. However, no differences were found in the negative regulator of cyclin/CDK, p27 and p21 between the two groups (data not shown), which requires further investigation. These results supported that CXCL10 promoted mesangial cell proliferation in MesPGN.

Previous studies have reported that CXCL10 and its receptor, CXCR3, could activate several classical signaling pathways, including ERK MAPK (p44/p42 mitogen-activated protein 


\section{Cellular Physiology Cell Physiol Biochem 2017;42:2118-2129 \begin{tabular}{l|l} 
DOI: 10.1159/000479914 & and Biochemistry \\
Published onthe; August 14, 2017 & $\begin{array}{l}\text { O 2017 The Author(s). Published by S. Karger AG, Basel } \\
\text { www.karger.com/cpb }\end{array}$
\end{tabular} \\ Gao et al.: the Mechanism of CXCL10 Promoting Mesangial Cell Proliferation.}

kinases) and PI3K (Akt/phosphatidylinositol-3-kinase), which are involved in regulation of cell growth [30, 41]. Fabio Marra et al. [42] and Mark O. Aksoy et al. [32] provided evidence that CXCL10 could activate the ERK cascade to modulate its biologic actions in hepatic stellate cells (HSC), human mesangial cells (HMC) and human bronchial epithelial cells (HBEC). To determine the specific mechanism by which CXCL10 modulates the pathological process of MesPGN, we detected the expression of phosphorylation ERK on day 7 using Western blot analysis. Cxcl $10 \%$ mice exhibited less activation of ERK phosphorylation compared with Cxcl10 $0^{+/+}$mice. To establish whether the ERK pathways are critical for the CXCL10-mediated proliferation of mesangial cells, MRMC were treated with recombinant murine CXCL10. The results of the EDU proliferation assay confirmed that CXCL10 induced the proliferation of MRMC. Then, we treated MRMC with specific inhibitors of the ERK signaling pathways before adding CXCL10. In the presence of U0126, the expression of ERK phosphorylation in CXCL10-stimulated primary MRMC was completely inhibited, indicating that ERK activation is required for CXCL10-induced mesangial cell proliferation.

\section{Conclusion}

In this study, Cxcl10-deficient mice were used to generate a MesPGN model for the first time. Through comparisons with wildtype mice, we found that CXCL10 expression positively correlates with MesPGN mesangial cell proliferation. Furthermore, we verified the proliferation effect induced by CXCL10 through activating the ERK signaling pathway in vitro, and this finding reveals potential intervention targets for treating mesangial cell injury disease.

\section{Abbreviations}

HSV (Habu Snake Venom); MesPGN (mesangial proliferative glomerulonephritis); MRMC (mouse renal mesangial cell); PAS (periodic acid-Schiff); PCNA (proliferating cell nuclear antigen); PDGF (platelet-derived growth factor); CDK2 (cyclin-dependent kinase 2); CDK4 (cyclin-dependent kinase 4); CDK6 (cyclin-dependent kinase 6); PAS (periodic acidSchiff.); HMC (human mesangial cells); HSC (hepatic stellate cells); HBEC (human bronchial epithelial cells).

\section{Acknowledgements}

This work was supported by grants from Programs of the National Natural Science Foundation of China ( 81330019, 81270794, 81670671, 81670694, 81470949), the National Basic Research Program of China (2013CB530800, 2015CB553605) and National Key Research and Development Plan (2016YFC1101403).

\section{Disclosure Statement}

No conflicts of interest.

\section{References}

1 Xie Y, Chen X: Epidemiology, major outcomes, risk factors, prevention and management of chronic kidney disease in China. Am J Nephrol 2008;28:1-7.

2 Kawasaki Y: The pathogenesis and treatment of IgA nephropathy. Fukushima J Med Sci 2008;54:43-60. 


\section{Cellular Physiology Cell Physiol Biochem 2017;42:2118-2129 \begin{tabular}{ll|l} 
DOI: 10.1159/000479914 & and Biochemistry 2017 The Author(s). Published by S. Karger AG, Basel \\
Published online: August 14, 2017 & \begin{tabular}{l} 
www.karger.com/cpb \\
\hline
\end{tabular}
\end{tabular}}

-3 Gomez-Guerrero C, Hernandez-Vargas P, Lopez-Franco 0, Ortiz-Munoz G, Egido J: Mesangial cells and glomerular inflammation: from the pathogenesis to novel therapeutic approaches. Curr Drug Targets Inflamm Allergy 2005;4:341-351.

4 Tamouza H, Chemouny JM, Raskova Kafkova L, Berthelot L, Flamant M, Demion M, Mesnard L, Paubelle E, Walker F, Julian BA, Tissandie E, Tiwari MK, Camara NO, Vrtovsnik F, Benhamou M, Novak J, Monteiro RC, Moura IC: The IgA1 immune complex-mediated activation of the MAPK/ERK kinase pathway in mesangial cells is associated with glomerular damage in IgA nephropathy. Kidney Int 2012;82:1284-1296.

5 Wada T, Matsushima K, Kaneko S: The role of chemokines in glomerulonephritis. Front Biosci 2008;13:3966-3974.

6 Wada T, Yokoyama H, Matsushima K, Kobayashi K: Chemokines in renal diseases. Int Immunopharmacol 2001;1:637-645.

7 Antonelli A, Ferrari SM, Giuggioli D, Ferrannini E, Ferri C, Fallahi P: Chemokine (C-X-C motif) ligand (CXCL)10 in autoimmune diseases. Autoimmun Rev 2014;13:272-280.

-8 Narumi S, Wyner LM, Stoler MH, Tannenbaum CS, Hamilton TA: Tissue-specific expression of murine IP-10 mRNA following systemic treatment with interferon gamma. J Leukoc Biol 1992;52:27-33.

-9 Luster AD, Unkeless JC, Ravetch JV: Gamma-interferon transcriptionally regulates an early-response gene containing homology to platelet proteins. Nature 1985;315:672-676.

10 Booth V, Keizer DW, Kamphuis MB, Clark-Lewis I, Sykes BD: The CXCR3 binding chemokine IP-10/CXCL10: structure and receptor interactions. Biochemistry 2002;41:10418-10425.

11 Luster AD: Chemokines--chemotactic cytokines that mediate inflammation. N Engl J Med 1998;338:436445.

12 Liu M, Guo S, Stiles JK: The emerging role of CXCL10 in cancer (Review). Oncol Lett 2011;2:583-589.

13 Romagnani P, Beltrame C, Annunziato F, Lasagni L, Luconi M, Galli G, Cosmi L, Maggi E, Salvadori M, Pupilli C, Serio M: Role for interactions between IP-10/Mig and CXCR3 in proliferative glomerulonephritis. J Am Soc Nephrol 1999;10:2518-2526.

14 Romagnani P, Lazzeri E, Lasagni L, Mavilia C, Beltrame C, Francalanci M, Rotondi M, Annunziato F, Maurenzig L, Cosmi L, Galli G, Salvadori M, Maggi E, Serio M: IP-10 and Mig production by glomerular cells in human proliferative glomerulonephritis and regulation by nitric oxide. J Am Soc Nephrol 2002;13:53-64.

15 Abrera-Abeleda MA, Xu Y, Pickering MC, Smith RJ, Sethi S: Mesangial immune complex glomerulonephritis due to complement factor D deficiency. Kidney Int 2007;71:1142-1147.

16 Jiang L, Liu G, Lv J, Huang C, Chen B, Wang S, Zou W, Zhang H, Wang H: Concise semiquantitative histological scoring system for immunoglobulin A nephropathy. Nephrology (Carlton) 2009;14:597-605.

17 Chen L, Lu Y, Wen J, Wang X, Wu L, Wu D, Sun X, Fu B, Yin Z, Jiang H, Chen X: Comparative Proteomics Analysis of Mouse Habu Nephritis Models with and without Unilateral Nephrectomy. Cell Physiol Biochem 2016;39:1761-1776.

18 Fang Y, Sun B, Xiang J, Chen Z: MiR-301a promotes colorectal cancer cell growth and invasion by directly targeting SOCS6. Cell Physiol Biochem 2015;35:227-236.

19 Liang Y, Zhang J, Zhou Y, Xing G, Zhao G, Liu Z: Proliferation and Cytokine Production of Human Mesangial Cells Stimulated by Secretory IgA Isolated from Patients with IgA Nephropathy. Cell Physiol Biochem 2015;36:1793-1808.

20 Dimmler A, Haas CS, Cho S, Hattler M, Forster C, Peters H, Schocklmann HO, Amann K: Laser capture microdissection and real-time PCR for analysis of glomerular endothelin-1 gene expression in mesangiolysis of rat anti-Thy 1.1 and murine Habu Snake Venom glomerulonephritis. Diagn Mol Pathol 2003;12:108-117.

-21 Ishizaki M, Masuda Y, Fukuda Y, Sugisaki Y, Yamanaka N, Masugi Y: Experimental mesangioproliferative glomerulonephritis in rats induced by intravenous administration of anti-thymocyte serum. Acta Pathol Jpn 1986;36:1191-1203.

22 Lu Y, Wen J, Chen D, Wu L, Li Q, Xie Y, Wu D, Liu X, Chen X: Modulation of cyclins and p53 in mesangial cell proliferation and apoptosis during Habu nephritis. Clin Exp Nephrol 2016;20:178-186.

23 Kouroumalis A, Nibbs RJ, Aptel H, Wright KL, Kolios G, Ward SG: The chemokines CXCL9, CXCL10, and CXCL11 differentially stimulate $G$ alpha i-independent signaling and actin responses in human intestinal myofibroblasts. J Immunol 2005;175:5403-5411.

24 Ohmori Y, Hamilton TA: Cell type and stimulus specific regulation of chemokine gene expression. Biochem Biophys Res Commun 1994;198:590-596. 


\section{Cellular Physiology Cell Physiol Biochem 2017;42:2118-2129 \begin{tabular}{ll|l} 
DOI: 10.1159/000479914 & and Biochemistry Published online: August 14, 2017 & $\begin{array}{l}\text { O 2017 The Author(s). Published by S. Karger AG, Basel } \\
\text { www.karger.com/cpb }\end{array}$
\end{tabular}}

25 Ohmori Y, Hamilton TA: The interferon-stimulated response element and a kappa B site mediate synergistic induction of murine IP-10 gene transcription by IFN-gamma and TNF-alpha. J Immunol 1995;154:52355244.

-26 van den Borne P, Quax PH, Hoefer IE, Pasterkamp G: The multifaceted functions of CXCL10 in cardiovascular disease. Biomed Res Int 2014;2014:893106.

27 Ohmori Y, Wyner L, Narumi S, Armstrong D, Stoler M, Hamilton TA: Tumor necrosis factor-alpha induces cell type and tissue-specific expression of chemoattractant cytokines in vivo. Am J Pathol 1993;142:861870.

-28 Sanchez-Lugo YE, Perez-Trujillo JJ, Gutierrez-Puente Y, Garcia-Garcia A, Rodriguez-Rocha H, BarbozaQuintana 0, Munoz-Maldonado GE, Saucedo-Cardenas O, de Oca-Luna RM, Loera-Arias MJ: CXCL10/XCL1 fusokine elicits in vitro and in vivo chemotaxis. Biotechnol Lett 2015;37:779-785.

29 Dominguez F, Martinez S, Quinonero A, Loro F, Horcajadas JA, Pellicer A, Simon C: CXCL10 and IL-6 induce chemotaxis in human trophoblast cell lines. Mol Hum Reprod 2008;14:423-430.

30 Schulthess FT, Paroni F, Sauter NS, Shu L, Ribaux P, Haataja L, Strieter RM, Oberholzer J, King CC, Maedler K: CXCL10 impairs beta cell function and viability in diabetes through TLR4 signaling. Cell Metab 2009;9:125139.

31 Yang LL, Ping C, Luo S, Li J, Liu K, Hu HZ, Wei YQ: CXCL10 gene therapy efficiently inhibited the growth of cervical carcinoma based on the antiangiogenic and antiviral activity. Biotechnology \& Applied Biochemistry 2009;53:209-216.

-32 Aksoy MO, Yang Y, Ji R, Reddy PJ, Shahabuddin S, Litvin J, Rogers TJ, Kelsen SG: CXCR3 surface expression in human airway epithelial cells: cell cycle dependence and effect on cell proliferation. Am J Physiol Lung Cell Mol Physiol 2006;290:L909-918.

-33 Tang WW, Yin S, Wittwer AJ, Qi M: Chemokine gene expression in anti-glomerular basement membrane antibody glomerulonephritis. Am J Physiol 1995;269:F323-330.

34 Topham PS, Csizmadia V, Soler D, Hines D, Gerard CJ, Salant DJ, Hancock WW: Lack of chemokine receptor CCR1 enhances Th1 responses and glomerular injury during nephrotoxic nephritis. J Clin Invest 1999;104:1549-1557.

-35 Perez de Lema G, Maier H, Nieto E, Vielhauer V, Luckow B, Mampaso F, Schlondorff D: Chemokine expression precedes inflammatory cell infiltration and chemokine receptor and cytokine expression during the initiation of murine lupus nephritis. J Am Soc Nephrol 2001;12:1369-1382.

-36 Lo DJ, Kaplan B, Kirk AD: Biomarkers for kidney transplant rejection. Nat Rev Nephrol 2014;10:215-225.

37 Ho J, Lucy M, Krokhin O, Hayglass K, Pascoe E, Darroch G, Rush D, Nickerson P, Rigatto C, Reslerova M: Mass spectrometry-based proteomic analysis of urine in acute kidney injury following cardiopulmonary bypass: a nested case-control study. Am J Kidney Dis 2009;53:584-595.

-38 Avihingsanon Y, Phumesin P, Benjachat T, Akkasilpa S, Kittikowit V, Praditpornsilpa K, Wongpiyabavorn J, Eiam-Ong S, Hemachudha T, Tungsanga K, Hirankarn N: Measurement of urinary chemokine and growth factor messenger RNAs: a noninvasive monitoring in lupus nephritis. Kidney Int 2006;69:747-753.

-39 Wu L, Chen X, Mei Y, Hong Q, Feng Z, Lv Y, Wen J, Liu X, Cai G, Chen X: CXCL10 expression induced by Mxi1 inactivation induces mesangial cell apoptosis in mouse Habu nephritis. Cell Signal 2015;27:943-950.

40 Bravo R, Frank R, Blundell PA, Macdonald-Bravo H: Cyclin/PCNA is the auxiliary protein of DNA polymerase-delta. Nature 1987;326:515-517.

-41 Zhai Y, Shen XD, Gao F, Zhao A, Freitas MC, Lassman C, Luster AD, Busuttil RW, Kupiec-Weglinski JW: CXCL10 regulates liver innate immune response against ischemia and reperfusion injury. Hepatology 2008;47:207-214.

42 Bonacchi A, Romagnani P, Romanelli RG, Efsen E, Annunziato F, Lasagni L, Francalanci M, Serio M, Laffi G, Pinzani M, Gentilini P, Marra F: Signal transduction by the chemokine receptor CXCR3: activation of Ras/ERK, Src, and phosphatidylinositol 3-kinase/Akt controls cell migration and proliferation in human vascular pericytes. J Biol Chem 2001;276:9945-9954. 